\title{
Update for the Neurology Residents and Fellows from the Neurology Residency Review Committee (NRRC)
}

\author{
Noah Rosen, MD*; Jasper R. Daube, MD†; and Larry Sulton, PhD
}

$\mathrm{T}$ he Accreditation Council for Graduate Medical Education (ACGME) has the mission of improving the quality of health care in the United States by ensuring and improving the quality of graduate medical education experience for physicians in training. The ACGME oversees 27 Residency Review Committees (RRC), including the Neurology Residency Review Committee (NRRC). Each RRC functions as the ACGME body that accredits specialty training programs. The Neurology RRC is comprised of seven members serving up to 6 years, two members each appointed by American Academy of Neurology, American Board of Professional Neuropsychology (ABPN), and the American Medical Association and a resident member serving 2 years. Two-thirds of the requirements for training programs are defined by the ACGME; the other third are specific to the specialty and defined by the RRC based on input from specialists in that field. The RRC and ACGME accomplish their goals by an in-depth review and subsequent accreditation of programs that meet the specified RRC requirements.

The Neurology RRC accredits adult and child neurology training programs and subspecialty training programs in clinical neurophysiology, vascular neurology, neurode- velopmental pediatrics, and pain management. Accreditation of sleep medicine programs will soon begin. The NRRC program accreditation is independent of the ABPN, which certifies individuals who have successfully completed an accredited training program. It is also independent of the AAN, which, among other things, is responsible for continuing education of neurologists who have completed their training. Each functions as an independent body working for the public good. This common philosophy has the ultimate goal of assuring the highest quality of care for patients with neurologic diseases.

Details of the activities of the NRRC are listed on the ACGME Web site at www.acgme.org (http:// www.acgme.org/). These include the following:

Lists of all approved adult, child, and subspecialty neurology training programs with descriptions of the programs

Requirements of all adult, child, and subspecialty neurology programs

Answers to frequently asked questions

Resident information including complaint procedures

Moonlighting policy
Specifics of the resident case log system

There are four major changes in requirements that will have an impact on neurology residents. First, new ACGME duty hour requirements specifically define how much time a resident or fellow may spend caring for patients. All RRCs are required to rigorously enforce these. Programs that do not comply will lose their accreditation. Loss of accreditation precludes future graduates of those programs from being certified in their specialty. Details are described on the Web site under resident information.

The second change is that all programs are being required to develop outcome-based core competencies that define what a resident or fellow must accomplish during the training period. The definitions are described as competencies that must be demonstrated during the training, rather than the experiences that had to be provided under the old rules. The ABPN will establish examinations that specifically test individual trainees for these competencies. Details of the core competency and outcomes program are also described on the ACGME Web site.

The third change is the requirement for demonstration of resident experience with a broad range of patients in their specialty. This will

\footnotetext{
* NRCC Resident Member.

$\dagger$ NRCC Chair.

$\ddagger$ NRCC Executive Director
}

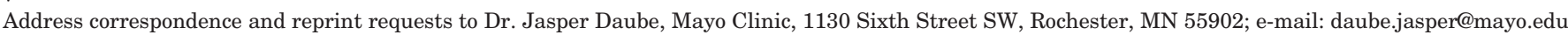


be accomplished through an ACGME Web-based program in which residents enter data about each new patient they evaluate. For surgeons, this includes the surgical procedures they perform. After a number of years of testing and piloting, the case log system will now be required for all neurology residents beginning in July 2004.

Program directors can request software programs for their residents who have personal digital assistants (PDA). If approved by a program director, the resident can download the program directly to their PDA to allow the entry of patient data at any time, with subsequent uploading to the ACGME. The 622 neurology residents in 32 programs who are already using the case log system have entered 50,650 diagnoses at an average of 1 minute per patient entry. A phone and Web-based help desk are available for residents having difficulty with data entry.

The fourth change for residents is a 1-month duty on psychiatry during PGY 2-4 under the supervision of a psychiatrist. This can be inpatient, outpatient, or both. It can also be configured into blocks of time or in longitudinal clinics equivalent to 1 month. This change recognizes the need for neurologists to handle patients with psychiatric disorders, and the new neurology trainee core competencies in psychiatry. It also makes the requirement for adult neurology trainees the same as that which has been in place for a number of years for child neurology trainees.

Additional information about the NRRC, including newsletters, is also available on the ACGME Web site. 


\section{Neurology}

\section{Update for the Neurology Residents and Fellows from the Neurology Residency Review Committee (NRRC)}

Noah Rosen, Jasper R. Daube and Larry Sulton

Neurology 2004;63;E2-E3

DOI 10.1212/WNL.63.1.E2

\section{This information is current as of July 12, 2004}

\section{Updated Information \&} Services

\section{Citations}

Permissions \& Licensing

Reprints including high resolution figures, can be found at: http://n.neurology.org/content/63/1/E2.full

This article has been cited by 1 HighWire-hosted articles: http://n.neurology.org/content/63/1/E2.full\#\#otherarticles

Information about reproducing this article in parts (figures,tables) or in its entirety can be found online at:

http://www.neurology.org/about/about_the_journal\#permissions

Information about ordering reprints can be found online: http://n.neurology.org/subscribers/advertise

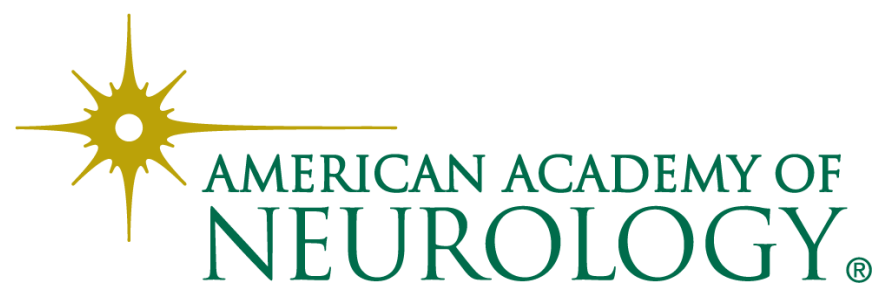

